\title{
Using virtual reality to enhances efforts for introduce cultural heritage
}

\author{
Zeinel Arfin Sadiq ${ }^{\mathrm{a}, 1, *}$ \\ ${ }^{a}$ Universitas Muhammadiyah Jember \\ Fakultas Ilmu Sosial dan Ilmu Politik, Gumuk Kerang, Karangrejo, Kec. Sumbersari, Kabupaten Jember, Jawa Timur 68124 \\ Program Studi Ilmu Komunikasi \\ ${ }^{1}$ Zeinalarifin@gmail.com*; \\ * corresponding author
}

Article history

Received 09-11-2021

Revised 10-11-2021

Accepted 11-11-2021

Keywords

Virtual-Reality

Introduce

Cultural Heritage

\begin{abstract}
At present, cultural heritage is in a dangerous condition and it is all influenced by several factors such as natural disasters and man-made disasters. For example, in Indonesia in March 2018 there was a destruction of the Dayak Indigenous Sites whose cases were damaged due to human factors, not to mention talking about the destruction of damaged cultural sites such as in several countries such as Iraq, Syria, Afghanistan \& Indonesia. The use of technology-based Virtual Reality (VR) in maintaining cultural heritage is very important because the identity that is in cultural heritage is the foundation of evidence of human life in the past. Threats in the form of human behavior and natural disasters have an impact of erasing historical and cultural traces which could threaten a nation in relation to the main national interests of a country. Maximizing the benefits of technological advancements by using Virtual Reality as an alternative to preserve cultural heritage \& cultural exploration, this utilization can lower the cost of study of cultural exploration such as exploration of cultural heritage locations.
\end{abstract}

This is an open access article under the CC-BY-SA license.

\section{Introduction}

Currently, cultural heritage is in a dangerous condition and it is all influenced by several factors such as natural disasters and man-made disasters. For example, in Indonesia in March 2018, there was the destruction of Dayak Customary Sites, which in this case was damaged due to human factors, not to mention that we are talking about the destruction of damaged cultural sites such as in several countries such as Iraq, Syria, Afghanistan \& Indonesia. whose damage occurred due to wars with several existing terrorist groups, such as in Indonesia on January 21, 1985 where nine stupas were damaged at Borobudur Temple due to terrorist attacks (Jandevi \& Zareen, 2020). Actually, cultural heritage itself according to the United Nations Educational, Scientific and Cultural Organization (UNESCO) cultural heritage is divided into two categories, namely tangible and intangible (UNESCO, 2018). What is tangible means that it exists physically and it has the risk of being damaged such as natural disasters or damage by humans. Therefore, this study discusses the importance of using Virtual Reality (VR) based technology in increasing efforts to preserve cultural heritage. Cultural heritage itself is related to sustainable development goals (SDGs), especially in number 11 point 11.4 which has the aim of creating inclusive, safe, resilient, and sustainable human and city settlements which have points in 11.4, namely Strengthening efforts to protect and protect cultural heritage and natural world. The use of VR-based technology in preserving cultural heritage is very important because the identity that exists in cultural heritage is the foundation of evidence of 
previous human life. Threats in the form of behavior from humans and natural disasters themselves which have the impact of eliminating historical and cultural traces will threaten a nation which is related to the main national interest in a country (United Nations Educational Scientific and Cultural Organization, 2018).

Based on the explanation background above, can be concluded that the problem formulation of this study are : (a) Why is the use of VR-based technology so important in improving efforts to preserve cultural heritage?. (b) How to use VR-based technology to improve efforts to preserve cultural heritage?. The objectives of this idea are as follows: (a) To explain the importance of preserving cultural heritage. (b) To explain how the VR efforts in preserving cultural heritage. (c) To provide solutions to the problems of the younger generation who are increasingly unfamiliar with their own culture (Zhang, 2019).

This study is used as a medium to convey an argument on a topic which is of course accompanied by valid and accountable data. Become academics who can interpret, collect and process data and test the cognitive abilities of writers. Fill in and revive the lack of discussion on the importance of using technology (one of which is VR) in an effort to preserve cultural heritage in Indonesia. Maximizing the benefits of technological advances by using Virtual Reality as an alternative to efforts to preserve cultural heritage \& cultural exploration, this utilization can lower the cost of studying cultural exploration such as exploration of distant cultural heritage locations, especially in transport costs. In addition, it can reduce the risk of the impact of the destruction of cultural heritage both by natural disasters and human disasters, and the latter can be considered as a reference in academic development for solutions to safeguarding and recognizing cultural heritage and providing solutions to problems in our country, namely the younger generation who are increasingly deprived. get to know the culture of your own country (Jandevi \& Zareen, 2020).

\section{Theorotocal Framework}

This study departs from the writing of a paper entitled 'Are you living in a simulation?'. Written by the Swedish philosopher Nick Bostrom in 2003. In this paper Bostrom states that future generations will be able to make very powerful computers that can hardly distinguish between reality and simulation.

Elon Musk as the Founder and Chief Executive of Space X during a discussion with the media about the threat of existential artificial intelligence. According to Musk, to overcome this threat, humans need to be melted with a machine. Musk claims there is a one-in-a-billion possibility that humans don't live in a simulation. Musk believes that humans live in computer simulations, this is supported by the emergence of Virtual Reality and Augmented Reality. This is supported by VR which has a social community platform such as VR chat or Facebook horizon where many people live interacting in a simulation of the virtual world (Fadillah, 2019).

Surveys funded by the Hasso-Plattner Institute, Augmented Reality Survey, Virtual Reality for cultural heritage have concluded that both Augmented Reality and Virtual Reality can achieve goals such as education, exploration, reconstruction of cultural heritage. (ACM Journal on Computing and Cultural Heritage, Vol. 11, No. 2, Article 7. Publication date: March 2018.)

The European Union in the results of the project entitled "ARCHEOGUIDE" obtained the result that the ancient ruins of cultural heritage from Greece can be reconstructed using the help of Augmented Reality technology.

Wang $\mathrm{Li}$ in his journal "Application of virtual reality technology in the inheritance of cultural heritage" concludes that cultural heritage can be applied in Virtual Reality and even many benefits will be obtained if cultural heritage is applied to the world of Virtual Reality.

Prof. Dr. Susanto Zuhdi in a book entitled "Integration of the Nation in the Indonesian Frame" argues that Indonesia is chaotic not because of physics but because of history. This is in line with cultural heritage, because cultural heritage also has a function as an identity for the historical origins of a nation that exists today (Zuhdi, 2017). 


\section{Method}

This article used descriptive qualitative method where technology become one of potential research within experimental studies base on web. In the future, this method can be learned more about human interaction creating collective behaviour in the society (Sugiyono, 2016).

\section{Results and Discussion}

Cultural heritage is a symbol of identity that describes who we are and also existing history. Culture itself is a basic need because it can unite the human community. Natural or unnatural destruction of cultural heritage can weaken morals and endanger humans because culture is a determining factor for the identity of human groups. The Sustainable Development Goals even include efforts to protect and protect the world's natural cultural heritage, because if cultural heritage is protected it will provide a sense of belonging, collective identity, a sense of inclusion and a sense of security because of the existence of Security Communities where people believe that their group members are not will fight physically to solve the problem but choose another path (Khairiah, 2020). Therefore, the importance of maintaining the same cultural heritage can create stability in various fields, because if the cultural heritage is preserved it will form a peaceful situation between various parties, this peaceful situation which causes stability in various fields. If all fields are stable, development involving the state and society can be encouraged and this is what is wanted to be achieved in several targets in the Sustainable Development Goals (SDGs) (Campelo, Reynolds, Lindgreen, \& Beverland, 2018).

\section{a. Mechanism for preserving cultural heritage utilizes VR-based technology}

On January 1, 2000 the European Union funded a project called the ARCHEOGUIDE project (Augmented Reality - based on cultural heritage on-site GUIDE) which ended on June 30, 2002. so this project created a system called ARCHEOGUIDE where the output of this system can reconstruct buildings ancient that's been destroyed.

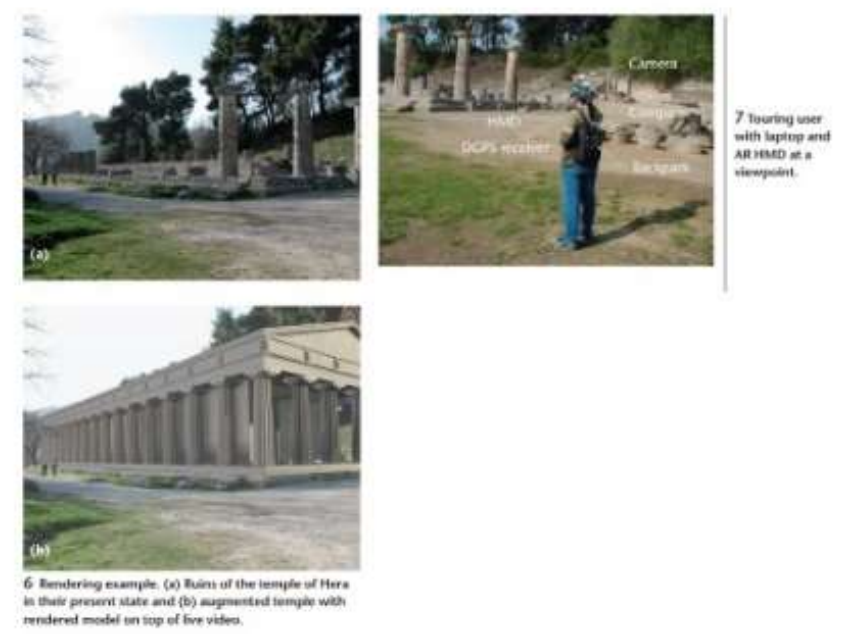

Fig. 1. Process of ARCHEOGUIDE in reconstruction of destroyed ancient buildings (https://www.researchgate.net/publication/3208993_Archeoguide_An_augmented_reality_guide_for_archaeo log_sites)

Since the technology for reconstructing buildings that have been destroyed exists, preserving cultural heritage will also be easier, even with just reconstruction using AR technology which makes it a 3D object without rebuilding the ancient building which was costly, but from reconstruction into 3D objects. those from AR itself were transferred to the world of Virtual Reality (VR). There are 2 ways to preserve cultural heritage in Virtual Reality, namely: 


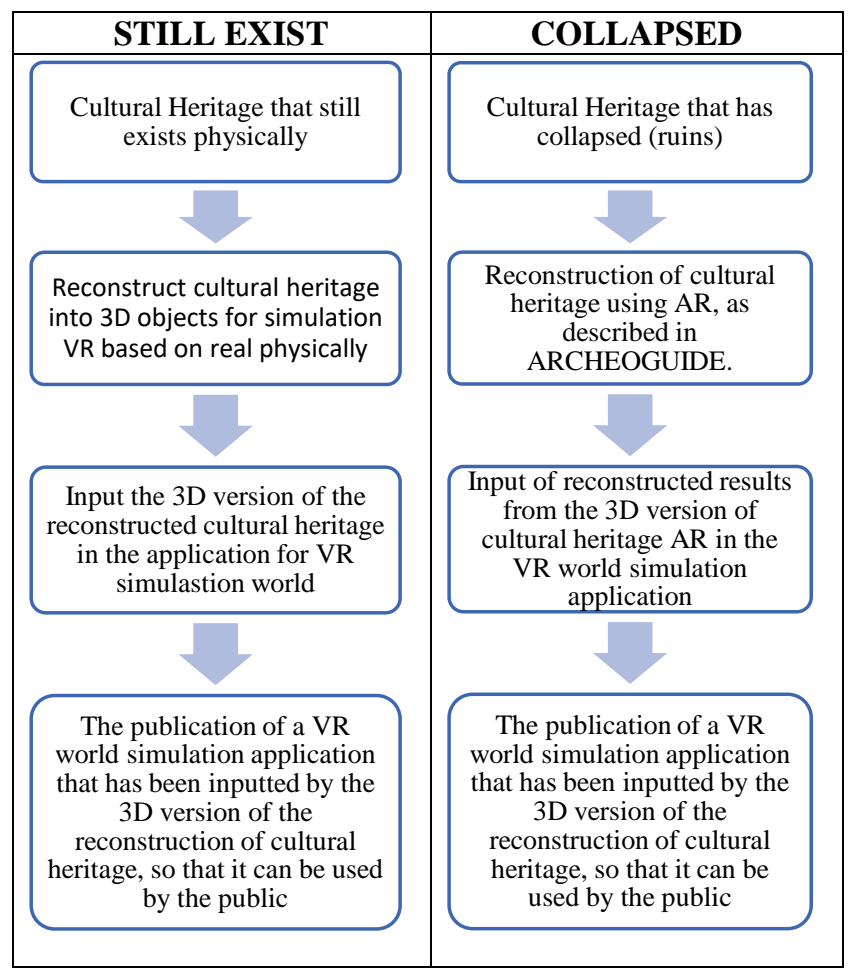

Fig. 2.Comparison between flowcharts of exist and collapes culture heritages

One of them is like a Virtual Reality simulation application entitled "Nefertari: Journey to Eternity". It is possible to explore the Egyptian cultural heritage, namely the tomb of Nefertari, even here the user can interact with ancient Egyptian symbols on the wall which will be given an explanation of the history, buildings, \& its mythology.

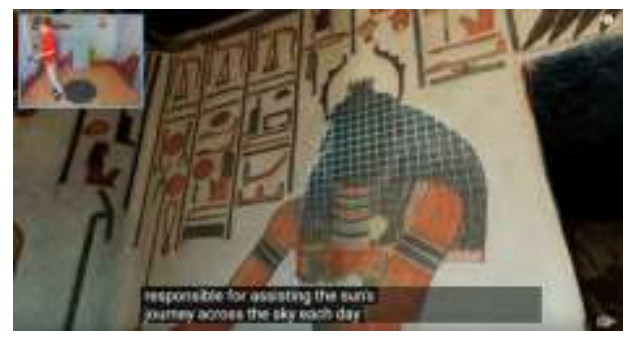

Fig. 3. Nathie is a YouTuber who tries the VR simulation Nefertari: Journey to Eternity, (https://www.youtube.com/watch?v=X0QO26aSx9M)

Similar to the paid Virtual Reality simulation application entitled "Olympia in VR" which allows to explore the cultural heritage of Ancient Greece, here the same user can interact with statues that have been explained about history, stories, \& mythology.

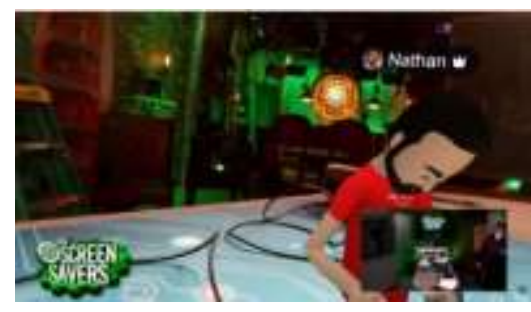

Fig. 4. Example from Facebook Spaces / Horizon, source, (https://www.youtube.com/watch?v=_kGRpSd4vnc) 


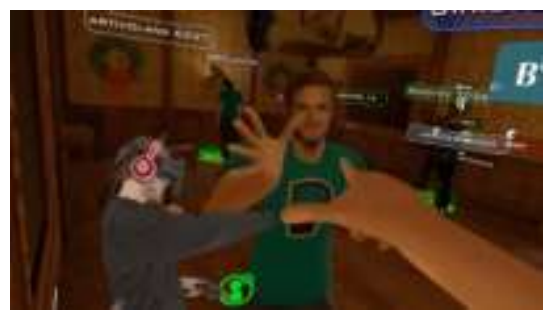

Fig. 5. Pewdiepie YouTuber who meets fans on VR Chat, (https://www.youtube.com/watch?v=IXdpjC7NHWc)

Cultural heritage reconstructed based on ARCHEOGUIDE or not the result of reconstruction is input into the VR world where it is safer from natural disasters and human disasters, and is more durable, is not a threat such as being exposed to corrosive and this is still rarely an application like this. It even makes it easier for people to study cultural heritage even though they don't have access to their original location, for example, I want to learn Japanese culture, so there will be no reason I find it difficult to learn because I am in Indonesia which is far from Japan, we just need to enter the VR world. and towards a reconstructed cultural place that we want to go to even if we need a tour guide like those who like to tell history, yes we just have to meet in the VR world, so the participants besides the government are the fundraisers for the project, so there are people who fill in the effort to protect them. this cultural heritage. in addition to preserving this cultural heritage, it also facilitates people's access to learning about foreign and non-foreign cultural cultures (Potts, 2019).

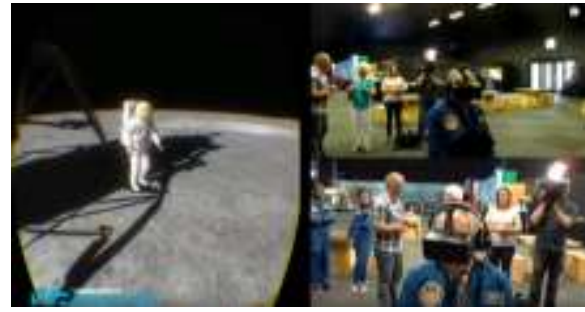

Fig. 6. Charlie Duke is an astronaut who immediately tried Appolo 11 VR

(https://www.youtube.com/watch?v=bLYjn8HiP1U)

\section{b. Solutions to the problems of the younger generation who do not care about their own culture (with government)}

For the manufacturing mechanism as described on page 8 , however, the government must be more intense in making cultural heritage in the virtual world and publish it for free so that access is not limited and this will provide a solution for the younger generation who are less concerned with their own culture if the heritage Our culture is packed with VR, so there will be many younger generations who are interested in trying to remember VR itself, the device that is currently being used to play games by the younger generation. 


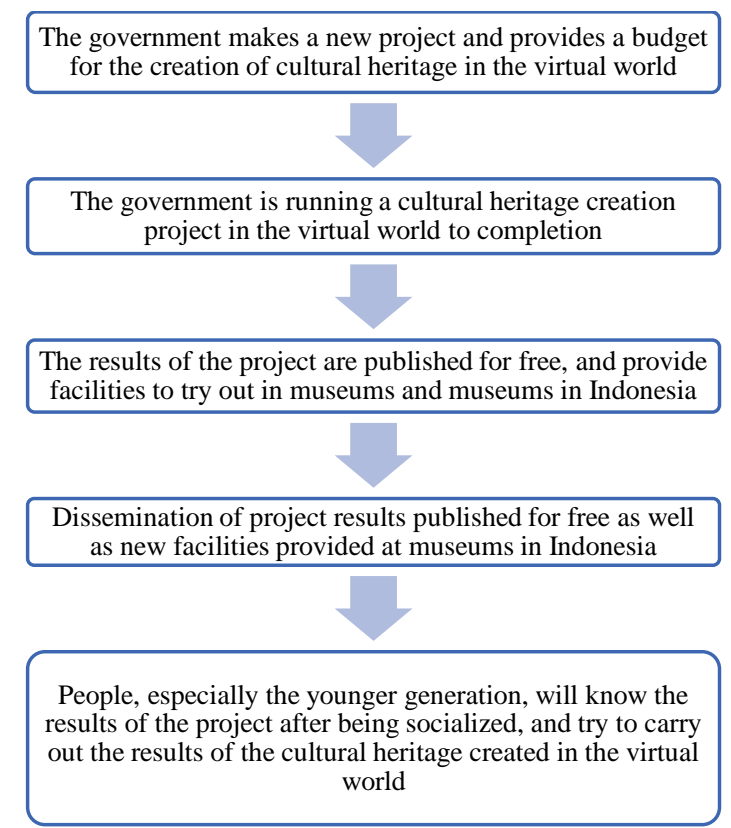

Fig. 7. Flowchart of solutions to the problem of the younger generation who do not care about their own culture (with government)

Actually, one of the museums in Indonesia already uses this VR technology to attract the attention of the younger generation and it works, but VR here is still just a simulation of a hot air balloon to see the museum from above, it would be great if the government imitated this but it was more perfect by making the world virtual cultural heritage and even simulations of historical stories such as Nefertari \& Apollo 11 VR.

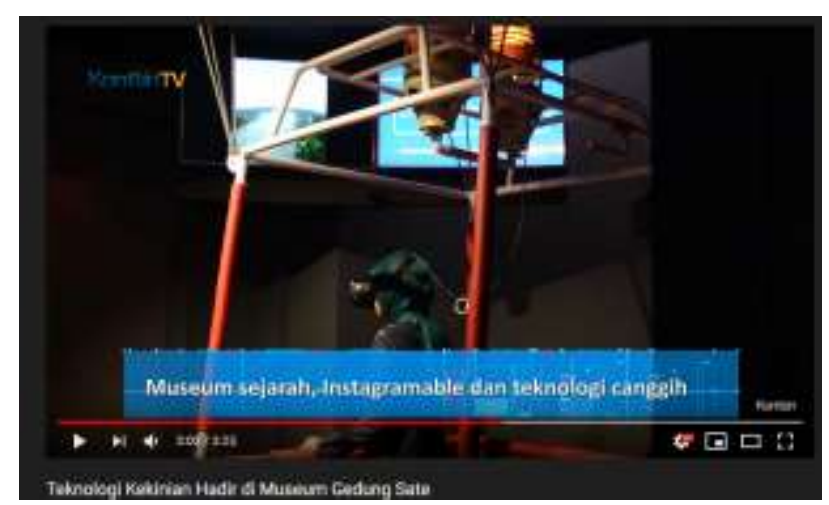

Fig. 8. Hot air balloon VR experiment at Gedung Sate Museum (https://www.youtube.com/watch? $v=R 84 t \operatorname{Tg} B X U Q$ )

Solutions to the problems of the younger generation who do not care about their own culture (Individual Project), For a solution that can be done individually by using a virtual tour but using camera 360 technology. Camera 360 itself is a camera that allows you to take pictures from all angles which can be seen from various sides. To overcome the solution to the problem of the younger generation who do not care about their own culture, what can be done is to design a virtual tour of a predetermined cultural heritage place and then publish it on the internet so that it can be accessed by all groups of society. 


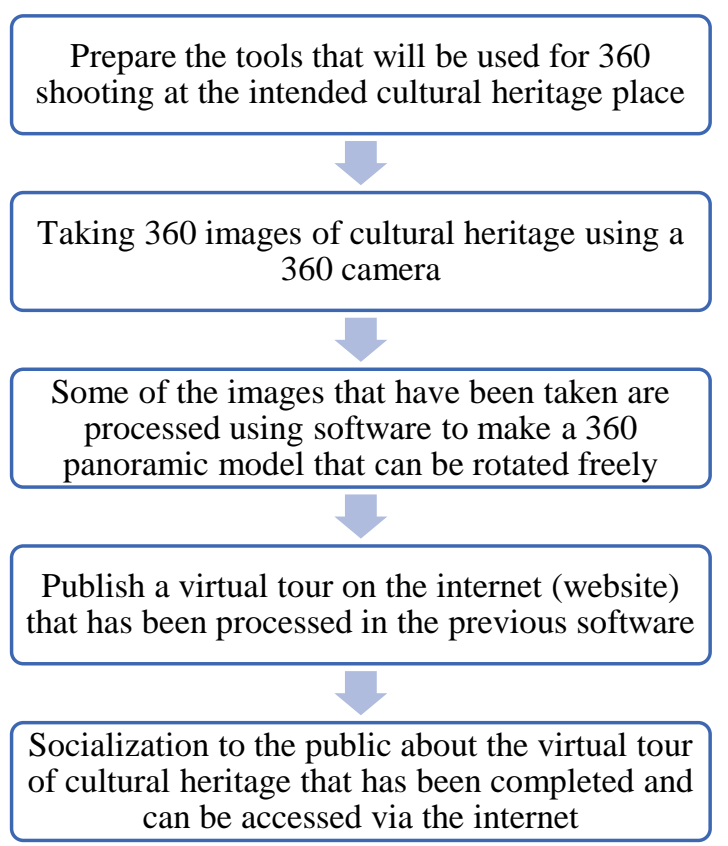

Fig. 9. Flowchart of solution to the problems of the younger generation who do not care about their own culture (Individual Project)

\section{Conclusion}

Cultural heritage is very important because it is the origin of the identity of a human group, the destruction of cultural heritage either through natural disasters or human disasters must be avoided because it is very detrimental. Thanks to the ARCHEOGUIDE project, humans are able to reconstruct destroyed ancient buildings through AR technology, then if the reconstruction results are put into the VR world, the risk of natural and human disasters is getting less and even access to study cultural heritage will be easier because we don't need to come to the location. physically, but we come to it through a VR world that has been inputted by a reconstruction of the existing cultural heritage. So the synergy between the government and the community in efforts to protect cultural heritage in accordance with sustainable development goals (SDGs), especially in number 11 point 11.4, will be easier if we implement it into the VR world.Authors and Affiliations.

The suggestion in this paper is that it is necessary to frequently fund projects that recreate cultural heritage and historical events into a virtual world (VR), it would be nice if this is also published for free for users because this will make it easier for us to protect cultural heritage, as well as to study and explore it.

\section{Acknowledgment}

First of all, thanks to my parents who have supported and prayed for me all this time. Then, I would like to thank the lecturer in communication science at the University of Muhammadiyah Jember who has helped me. And at last, I would like to thank my fellow students who have supported me.

\section{References}

Campelo, A., Reynolds, L., Lindgreen, A., \& Beverland, M. (2018). Cultural heritage. In Cultural Heritage. https://doi.org/10.4324/9781315107264

Fadillah, D. (2019). SOCIAL MEDIA AND GENERAL ELECTION IN SOUTHEAST ASIA (MALAYSIA 2018 AND INDONESIA 2019). Jurnal Komunikasi: Ikatan Sarjana Komunikasi Indonesia, 4(1). https://doi.org/10.25008/jkiski.v4i1.255

Jandevi, U., \& Zareen, M. (2020). Cross-cultural communication of the Indonesian students in China. International Journal of Communication and Society, 2(2), 79-85. https://doi.org/10.31763/ijcs.v2i2.96 
Khairiah, M. (2020). Louiz Zamperini's American Dreams as Reflected in the Film Unbroken. Commicast, 1(2), 33. https://doi.org/10.12928/commicast.v1i2.2727

Potts, T. (2019). Popular culture. Year's Work in Critical and Cultural Theory. https://doi.org/10.1093/ywcct/mbz018

Sugiyono, P. D. metode penelitian kuantitatif, kualitatif,dan R\&D. , Alfabeta, cv. (2016).

UNESCO. (2018). The United Nations world water development report 2018: Nature-Based Solutions for Water. In Unesco.

United Nations Educational Scientific and Cultural Organization. (2018). International technical guidance on sexuality education: An Evidence-informed Approach. In Unesco.

Zhang, Y. Z. (2019). Virtual reality technology. In Digital Orthopedics. https://doi.org/10.1007/978-94-0241076-1_3

Zuhdi, S. (2017). The Character of Maritime Nation In Facing The Global Challenge: A Historical Perspective. Historia: Jurnal Pendidik Dan Peneliti Sejarah. https://doi.org/10.17509/historia.v13i2.6213 